\title{
BMJ Open Healthcare professionals knowledge, attitude and practice of adverse drug reactions reporting in Ethiopia: a cross- sectional study
}

\author{
Kidu Gidey (1) , Mohammedamin Seifu, Berhane Yohannes Hailu,
} Solomon Weldegebreal Asgedom, Yirga Legesse Niriayo

To cite: Gidey K, Seifu M, Hailu BY, et al. Healthcare professionals knowledge, attitude and practice of adverse drug reactions reporting in Ethiopia: a crosssectional study. BMJ Open 2020;10:e034553. doi:10.1136/ bmjopen-2019-034553

- Prepublication history for this paper is available online. To view these files, please visit the journal online (http://dx.doi org/10.1136/bmjopen-2019034553).

Received 26 September 2019 Revised 13 January 2020 Accepted 04 February 2020

\section{Check for updates}

\section{(c) Author(s) (or their} employer(s)) 2020. Re-use permitted under CC BY-NC. No commercial re-use. See rights and permissions. Published by BMJ.

Department of Clinical Pharmacy, School of Pharmacy, College of Health Sciences, Mekelle University, Mekelle, Ethiopia

Correspondence to

Kidu Gidey;

kidupharm@gmail.com

\section{ABSTRACT}

Objective This study aimed to assess the knowledge, attitude and practice of adverse drug reactions (ADRs) reporting and identify factors associated with ADRs reporting among healthcare professionals (HCPs) working in Tigray region, Ethiopia.

Materials and methods A cross-sectional study was conducted between January and March of 2019 in a tertiary care hospital in Tigray region, Ethiopia. A selfadministered, pretested questionnaire was administered to HCPs. Data were summarised using descriptive statistics. Logistic regression analysis was used to identify factors associated with poor ADRs reporting practices.

Results In total, 362 questionnaires were distributed, and the response rate was $84.8 \%(n=307)$. Of all respondents, $190(61.9 \%)$ were nurses, $63(20.5 \%)$ were pharmacist and $54(17.6 \%)$ were physicians. About $58.3 \%$ of HCPs had poor knowledge of ADRs reporting. The majority of the respondents had a positive attitude $(59.9 \%)$, and only a few $(32.1 \%)$ respondents have good ADRs reporting practices. Poor knowledge (adjusted OR $(A O R)=2.63,95 \%$ Cl: 1.26 to 5.45 ) and lack of training on ADRs reporting ( $A O R=7.31,95 \% \mathrm{Cl}: 3.42$ to 15.62 ) were both negatively associated with ADRs reporting practice, whereas higher work experience ( 210 years) (AOR $=0.36,95 \% \mathrm{Cl}: 0.13$ to 0.97 ) was positively associated with ADRs reporting practice.

Conclusions The majority of HCPs had poor knowledge and practice, but a positive attitude towards ADRs reporting. Poor knowledge, less work experience and lack of training were associated with poor ADRs reporting practice. Hence, strategies to improve the knowledge and practice of ADRs reporting should be implemented, particularly for untrained and less experienced HCPs.

\section{INTRODUCTION}

Adverse drug reactions (ADRs) are a major cause of morbidity and mortality and contribute to the occurrence of adverse events, leading to increased healthcare costs. ${ }^{1}$ ADRs have become a major public health problem in developing countries. ${ }^{2}$ The median prevalence (with IQR of ADR-related hospitalisation in developing countries
Strengths and limitations of this study

- As strengths, this study included a good number of healthcare professionals (HCPs) and includes nurses and pharmacists as well as physicians.

- Data collection was conducted prospectively, and adjustment for confounding factors was performed with logistic regression analysis.

- There is a possibility that HCPs may not report their actual adverse drug reactions (ADRs) reporting practices since the information was self-reported.

- The cross-sectional design of this study may not establish a causal relationship between ADRs reporting and explanatory variables.

- Our study was conducted in a single centre and may not be generalisable to HCPs in other hospitals.

was $5.5 \% \quad(1.1-16.9) .^{3}$ The information collected during the pre-marketing phase of drug development is inevitably incomplete concerning possible ADRs. This is due to the participation of a limited and selected number of patients who are studied before marketing, the conditions of drug use in clinical trials are different from those of clinical practice, the duration of the clinical trials is short, and high-risk patients (such as elderly patients) are often excluded. ${ }^{4}$ Therefore, post-marketing surveillance is important to allow detection of less common, but sometimes very serious ADRs. Once a drug is registered and marketed, adverse reaction studies can be conducted using a variety of methods, such as observational studies, monitoring of prescription events, spontaneous reports and so on. ${ }^{5}$ However, the healthcare system relies heavily on spontaneous ADRs reporting to monitor drug safety throughout the population during actual use. ${ }^{6}$

A spontaneous reporting system of ADRs is fundamental to effectively discover new adverse reactions but under-reporting is 
its major limitations. ${ }^{78}$ A systematic review of studies conducted in the European Union showed a significant and widespread healthcare professionals (HCPs) underreporting of ADRs with a median rate of under-reporting of $94 \% .^{7}$ The low rates of ADRs reporting may delay regulatory actions to remove drugs with an unacceptable safety profile from the marketplace. A worldwide systematic review of 462 medicines removed from the market for safety reasons showed that the median interval between the first reported adverse reaction and the year of first withdrawal was 6 years (IQR, 1-15) and the interval did not consistently shorten over time. ${ }^{9}$

HCPs are responsible for identifying, documenting and ADRs reporting. Their contribution to the early detection and reporting of ADR is essential. ${ }^{10}$ However, ADR reporting is affected by many factors, including lack of awareness, ambiguity about who should report, difficulties with reporting procedures, lack of feedback on submitted reports, rapid resolution of adverse events and so on. ${ }^{11} 12$ The knowledge and attitudes of health professionals are strongly related to ADRs reporting. ${ }^{813}$ Therefore, it is very important to understand the knowledge and practice of healthcare providers related to ADR reporting to improve reporting practices. ${ }^{14}$

Although local regulatory authorities can make drug safety decisions using ADR data from other countries, it is essential to take into account a number of factors, such as local population traditions, genetics, diet and environmental factors. ${ }^{15}$ Therefore, it is very important to establish a local functional ADR monitoring centre. Ethiopia established its own pharmacovigilance system under the Food and Drug Administration and control authority in 2002. Since the introduction of the pharmacovigilance system, only a small number of ADRs have been reported to the centre. ${ }^{16}$ Besides, studies on identifying factors and reasons for poor reporting practices are limited in our context. The aim of this study was therefore to determine the knowledge, attitudes and practices of ADRs reporting and to identify predictive factors for poor ADR reporting practices among health professionals in a tertiary hospital in the Tigray region, Ethiopia.

\section{MATERIALS AND METHODS \\ Study setting and period}

The study was conducted at Ayder comprehensive specialised hospital (ACSH), Tigray region, Northern Ethiopia. ACSH is a teaching and referral hospital with 500 beds. The hospital serves more than nine million people in the catchment area. ACSH provides all the specialised and non-specialised hospital services including emergency services, outpatient services and inpatient services. HCPs working in all of these areas were included in this study between January and March of 2019.

\section{Study design and population}

An institutional-based cross-sectional study was conducted. The target populations for this study were nurses, physicians and pharmacists working in ACSH during the study periods. HCPs who were refused or did not wish to participate in the study were excluded.

\section{Sample size determination and sampling technique}

The sample size was calculated using a single proportion sample size estimating formula

$$
\mathrm{n}=\frac{(\mathrm{z} 1-\alpha / 2)^{2} \mathrm{P}(1-\mathrm{P})}{\mathrm{d}^{2}}=\frac{(1.96)^{2} 0.66(1-0.66)}{0.05^{2}}=344.8 \approx 345
$$

where $\mathrm{n}=$ sample size, $\mathrm{Z}=$ confidence interval (1.96), $\mathrm{p}=$ the proportion of HCPs with poor knowledge of ADR reporting (65.8, $\mathrm{p}=0.66)$, obtained from a study conducted in Amhara region of Ethiopia ${ }^{17}$ and $\mathrm{d}=$ margin of error to be tolerated (0.05). By adding $5 \%$ $(345 \times 0.05=17.25)$ of the sample size to compensate non-respondents, the total sample size required was 362. Subjects were recruited using stratified random sampling technique. A list of HCPs (pharmacists, physicians and nurses) working at the hospital was obtained from the hospital's human resources department. All HCPs were first stratified according to the type of profession and this list was used as a sampling frame. Depending on the size of the profession in each category of HCPs, participants were randomly selected. We used a lottery method to randomly select a set of HCPs as respondents from each category. We used this lottery method from the complete list of each category assuming that all the HCPs working in a similar profession (for example, all physicians) in different departments and/or units were homogeneous with respect to knowledge, attitude and practice of ADRs reporting.

\section{Outcome measures}

In this survey, knowledge of ADR reporting was assessed using nine questions containing general knowledge about ADR and ADR reporting. Each correct answer had a score of 1 and each wrong answer had a score of 0 . Thus, the total score ranged from 0 to 9 points. The overall level of knowledge was categorised using the median score. Participants with above median scores were classified as having good knowledge and below the median scores were classified as having poor knowledge. Participants' attitudes were assessed using ten items rated as agreeing, neutral and disagreeing on a three-point Likert scale. The 'agree' responses received a score of 3, 'neutral' a score of 2 and 'disagree' a score of 1 . An inverted score was made for the negativeworded questions. Therefore, the maximum possible attitude score was 30 . The median attitude score was calculated for each respondent, on the basis of which their attitude was categorised as positive and negative. The level of practice of health professionals was assessed by determining whether they had encountered, documented and reported ADRs or not. Participants were classified as having good practice if they had reported one or more ADRs and poor practices, if they had never reported ADR, despite encountering ADRs. 


\section{Data collection}

The Data Collection Tool is a questionnaire that was adopted from similar previous studies on the knowledge, attitudes and practices of HCPs on ADR reporting. ${ }^{18-20}$

The questionnaire was reviewed for its content validity by consensus of a panel of three experts in the field derived from academia (one expert from pharmacoepidemiology and two experts from clinical pharmacy departments). The Index of consistency of the questionnaires was 0.86 , suggesting that the questions strictly adhered to the objectives of the study. A pre-test was performed on $5 \%$ of the sample (19 HCPS) in a different hospital and face validity of the questionnaire was tested. Minor modifications have been made accordingly to avoid ambiguities and improve clarity. These participants were not included in the final study.

The prepared self-administered questionnaire contained four different sections. The first section contained demographic information. The second section consists of nine questions used to measure the knowledge of HCPs related to ADR reporting. The third section consisted of ten questions, which assessed participants' attitudes towards ADR reporting. The fourth section is about the practice of ADR reporting. The questionnaires were distributed by two pharmacists in person. The completed questionnaires were then collected by the pharmacists in person at the end of the first, second, third and fourth weeks. A remainder was provided to non-respondents twice (ie, at the end of the second week and the end of the third week). If the questionnaires did not return by the end of the fourth week, the participant was considered non-respondent.

\section{Statistical methods}

The data were coded, double-entered into Epi data management (V. 4.2.0), and statistical analysis was performed using STATA V. 14.1 (STATA Corp, College Station, Texas, USA). Descriptive analysis was computed using mean (SD) and median (IQR) for quantitative variables and frequency for categorical variables. To determine the factors associated with ADR reporting, univariate and multivariate logistic regression tests were used. The dependent variable was ADR reporting, while demographics, knowledge and attitude were included as the independent variables. Values were considered significant at a $p$ value of $<0.05(\alpha=0.05)$.

\section{Patient and public involvement}

As the study focused on the knowledge, attitudes and practices of HCPs, patients or members of the public were not directly involved in the design or planning of this research study.

\section{RESULTS}

\section{Demographic characteristics}

In the current study, 362 questionnaires were distributed. Of these, 307 were duly completed and returned, giving a
Table 1 Sociodemographic characteristics of respondents at $\mathrm{ACSH}$, Tigray Region, Northern Ethiopia, from January 2019 to March $2019(n=307)$

\begin{tabular}{lc}
\hline Variable & Frequency (\%) \\
\hline Sex & $156(50.8)$ \\
\hline Male & $151(49.2)$ \\
\hline Agemale & \\
\hline$<25$ & $63(20.5)$ \\
\hline $25-34$ & $199(64.8)$ \\
$\geq 35$ & $45(14.7)$ \\
\hline Mean \pm SD & $29.1 \pm 4.3$ \\
\hline Median (range) & $28(23-51)$ \\
\hline Profession & \\
\hline Physician & $54(17.6)$ \\
\hline Pharmacy & $63(20.5)$ \\
\hline Nurse & $190(61.9)$ \\
\hline Work experience (years) & \\
\hline$<5$ & $156(50.9)$ \\
\hline $5-9$ & $121(40)$ \\
\hline Trained on ADR reporting & $28(9.1)$ \\
\hline Yes & $138(44.95)$ \\
\hline No & \\
\hline ADR, & \\
\hline
\end{tabular}

ADR, adverse drug reaction.

response rate of $84.8 \%$. Of all respondents, $190(61.9 \%)$ were nurses, $63(20.5 \%)$ were pharmacist and $54(17.6 \%)$ were physicians. About $50 \%$ of respondents have less than 5 years of experience and more than half of the participants had not received any training on ADRs (table 1).

\section{Knowledge of ADR reporting}

There were nine questions assessing knowledge of ADRs. Only $29.3 \%$ of respondents knew the exact definition of adverse reactions and $36.8 \%$ of respondents knew what to report. A small proportion of respondents (19.5\%) were aware of the classification of ADRs. Of the respondents, $39.4 \%$ of the respondents felt they were aware of the availability of the National Reporting Center in Ethiopia and a small proportion of the respondents $(31.9 \%)$ knew where to report. The median with IQR of the level of knowledge of ADRs reporting among HCPs was 4 (3-6). Overall, the majority $(58.3 \%)$ of health professionals had poor knowledge of ADR reporting (table 2).

\section{Attitude of health professionals towards ADR reporting}

Regarding HCPs' attitudes to ADRs reporting, the majority $(67.4 \%)$ of respondents agreed that it is necessary to report, while $37.8 \%$ agreed that ADRs reporting should be mandatory. Most respondents (51.1\%) disagreed with the idea that only prescribed medication 
Table 2 Knowledge of healthcare professionals towards ADR reporting in ACSH, Tigray region, Northern Ethiopia, from January 2019 to March $2019(n=307)$

\section{Variables}

Frequency

(\%)

Which of the following defines ADR correctly?

Any noxious or undesired effect of drug

$90(29.3)$ occurring at normal dose, during normal use*

Adverse health outcomes associated with inappropriate drug use

$51(16.6)$

Harm resulting from the use of substandard/ 26 (8.5) counterfeit drugs

Harm caused by drug overdose

$67(21.8)$

All can define ADR $73(23.8)$

Which ADR should be reported?

All series ADRs

$113(36.8)$

ADRs to herbal and non-allopathic drugs 15 (4.9)

ADRs to new drugs

$49(16.0)$

ADRs to vaccines drugs

8 (2.6)

Unknown ADRs to old drugs

$9(2.9)$

All of the above* $113(36.8)$

The correct classification of the type of ADR

$\begin{array}{ll}\text { Type A, B, C, D, E and F* } & 60(19.5) \\ \text { Type 1, 2, 3, 4, 5, } 6 \text { and } 7 & 62(20.2) \\ \text { Known, unknown and common, uncommon } & 89(29.0) \\ \text { Reversible and irreversible } & 64(20.8) \\ \text { Do not know } & 31(10.1)\end{array}$

Is there any centre/ADR reporting system in Ethiopia

$\begin{array}{lr}\text { Yes* }^{\star} & 121(39.4) \\ \text { No } & 141(45.9) \\ \text { Do not know } & 45(14.7)\end{array}$

All ADRs are known before a medicine is marketed.

$\begin{array}{lr}\text { Yes } & 99(32.2) \\ \text { No* } & 168(54.7) \\ \text { Do not know } & 40(13.0)\end{array}$

Are you aware of any drug that banned due to ADR?

\begin{tabular}{lr}
\hline Yes $^{*}$ & $98(31.9)$ \\
\hline No & $176(57.3)$ \\
\hline Do not know & $33(10.7)$ \\
\hline Where are ADRs reported in Ethiopia? & $17(5.5)$ \\
\hline Manufacturers & $68(22.1)$ \\
\hline Ministry of Health of Ethiopia & $47(15.3)$ \\
\hline Ethiopian pharmaceutical association & $49(16.0)$ \\
\hline DTC of respective health facility & $98(31.9)$ \\
\hline FMHACA* & \\
\hline
\end{tabular}

Continued
Table 2 Continued

\begin{tabular}{|c|c|}
\hline Variables & $(\%)$ \\
\hline Pharmacy dept & $28(9.1)$ \\
\hline \multicolumn{2}{|c|}{$\begin{array}{l}\text { Do you think that ADR is the same with side } \\
\text { effects? }\end{array}$} \\
\hline Yes & $127(41.4)$ \\
\hline $\mathrm{No}^{*}$ & $180(58.6)$ \\
\hline \multicolumn{2}{|c|}{$\begin{array}{l}\text { Which of the following is the major risk factor } \\
\text { for the occurrence of maximum ADRs }\end{array}$} \\
\hline Arthritis & $30(9.8)$ \\
\hline Renal failure* $^{*}$ & $147(47.9)$ \\
\hline Visual impairment & $24(7.8)$ \\
\hline All of these & $106(34.5)$ \\
\hline \multicolumn{2}{|c|}{ Overall knowledge score } \\
\hline Good & $128(41.7)$ \\
\hline Poor & $179(58.3)$ \\
\hline
\end{tabular}

${ }^{*}$ Correct answers.

ADR, adverse drug reaction; DACA, Drug Administration and Control Authority; DTC, drug and therapeutic committee;

FMHACA, Food, Medicine and Healthcare Administration and Control Authority; STG, standard treatment guideline.

should be reported. The median (IQR) of the attitude score of ADRs reporting among HCPs was 20 (17-22). Overall, about $60 \%$ of respondents showed a positive attitude towards ADRs reporting (table 3).

\section{Practices of health professionals about ADR reporting}

Of the 307 health professionals, $74.9 \%$ encountered ADR in the last 12 months of their clinical practice, and $29.1 \%$ of them recorded in patient cards. Although most HCPs experienced ADR, only $32.1 \%$ reported it (table 4 ).

\section{Factors associated with poor ADR reporting practice}

A univariable logistic regression analysis was performed to determine the association of each variable with the practice of ADR reporting. In the univariable analysis work experience of the HCPs ( $\geq 10$ years) (unadjusted $\mathrm{OR}=0.31,95 \%$ CI: 0.15 to 0.64 ), negative attitude (unadjusted $\mathrm{OR}=2.08$, 95\% CI: 1.17 to 3.72 ), poor knowledge (unadjusted OR=3.49, 95\% CI: 1.95 to 6.23 ), lack of training on $\mathrm{ADR}$ reporting (unadjusted $\mathrm{OR}=7.67$, 95\% CI: 4.07 to 14.46 ) and nursing profession (unadjusted $\mathrm{OR}=2.11,95 \% \mathrm{CI}: 1.06$ to 4.20 ) were associated with poor ADR reporting practice. A subsequent multivariable logistic regression model was conducted to identify the independent predictors. The full model containing all predictors was statistically significant $\left(\chi^{2}=69.78, \mathrm{df}=10\right.$, $\mathrm{p}$ value $<0.001)$. The results of the multivariate logistic regression indicated that only work experience of the HCPs $(\geq 10$ years $)$ (adjusted OR $(\mathrm{AOR})=0.36,95 \% \mathrm{CI}$ : 0.13 to 0.97 ), poor knowledge ( $\mathrm{AOR}=2.63,95 \% \mathrm{CI}$ : 1.26 to $5.45)$ and lack of training on $\mathrm{ADR}$ reporting $(\mathrm{AOR}=7.31$, 
Table 3 Attitude of healthcare professionals towards ADR reporting in ACSH, Tigray region, Northern Ethiopia, from January 2019 to March 2019 ( $n=307)$

\begin{tabular}{|c|c|c|c|}
\hline \multirow[b]{2}{*}{ Items } & \multicolumn{3}{|l|}{ Responses } \\
\hline & Agree, n (\%) & Neutral, n (\%) & Disagree, n (\%) \\
\hline ADR reporting is necessary & $207(67.4)$ & $23(7.5)$ & $77(25.1)$ \\
\hline ADR reporting increase patient's safety & $148(48.2)$ & $66(21.5)$ & $93(30.3)$ \\
\hline ADR reporting is important for healthcare system & $135(44.0)$ & $73(23.8)$ & $99(32.2)$ \\
\hline One report of ADR makes no differences & $103(33.6)$ & $78(25.4)$ & $126(41.0)$ \\
\hline The yellow card is difficult to fill up & $177(57.7)$ & $88(28.7)$ & $42(13.7)$ \\
\hline ADR reporting creates additional workload and it is time consuming & $199(64.8)$ & $78(25.4)$ & $30(9.8)$ \\
\hline Establishing ADR reporting centre in every hospital is important & $189(61.6)$ & $44(14.3)$ & $74(24.1)$ \\
\hline
\end{tabular}

ADR, adverse drug reaction; HCP, healthcare professional.

95\% CI: 3.42 to 15.62$)$ were the predictors of poor ADR reporting practice (table 5 ).

\section{DISCUSSION}

One of the main goals of this study was to investigate the knowledge of HCPs towards ADRs reporting. This issue is critical for research to identify the necessary interventions, as HCPs cannot effectively participate in the reporting without sufficient knowledge of the ADR and its reporting process. We found that only $41.7 \%$ of HCPs had good knowledge about ADR reporting, similar to the reports seen in Amhara region of Ethiopia (47\%). ${ }^{21}$ Lack of training on ADRs reporting was significantly associated with insufficient knowledge of ADRs reporting in a study conducted in the Amhara region $(\mathrm{p}=0.037) .{ }^{21}$ Similarly, in our study, more than half of the participants were

Table 4 Practice of healthcare professionals towards ADR reporting in ACSH, Tigray region, Northern Ethiopia, from January 2019 to March $2019(n=307)$

\begin{tabular}{|c|c|c|}
\hline Items & Category & Frequency (\%) \\
\hline \multirow{2}{*}{$\begin{array}{l}\text { Have you ever encountered patient with ADR in your clinical practice in the last } \\
12 \text { months? }\end{array}$} & Yes & $230(74.9)$ \\
\hline & No & $77(25.1)$ \\
\hline \multirow{4}{*}{ How many patients with ADR have you encountered during the last 12 months? } & 1 & $13(4.2)$ \\
\hline & 2 & $58(18.9)$ \\
\hline & 4 & $52(16.9)$ \\
\hline & More than 4 & $46(15.0)$ \\
\hline \multirow{2}{*}{$\begin{array}{l}\text { Have you noted the ADR you encountered on the patient clinical record? } \\
(n=230)\end{array}$} & Yes & $67(29.1)$ \\
\hline & No & $163(70.9)$ \\
\hline \multirow{2}{*}{$\begin{array}{l}\text { How often do you give advice to your patients on possible ADRs you } \\
\text { prescribed, dispensed or administered }\end{array}$} & Usually & $118(38.4)$ \\
\hline & Always & $31(10.1)$ \\
\hline \multirow[t]{2}{*}{ If you encountered ADR, have you ever reported the ADR? $(n=230)$} & Yes (good practice) & $74(32.1)$ \\
\hline & No (poor practice) & $156(67.9)$ \\
\hline
\end{tabular}

ADR, adverse drug reaction. 
Table 5 Univariable and multivariable logistic regression analysis of associated factors of poor ADR reporting practice in Tigray region, Ethiopia from January 2019 to March $2019(n=230)$

\begin{tabular}{|c|c|c|c|c|c|c|}
\hline \multirow[b]{2}{*}{ Variable } & \multicolumn{2}{|c|}{ ADR reporting practice } & \multirow[b]{2}{*}{$P$ value } & \multirow[b]{2}{*}{ Unadjusted OR $(95 \% \mathrm{Cl})$} & \multirow[b]{2}{*}{ AOR $(95 \% \mathrm{Cl})$} & \multirow[b]{2}{*}{$P$ value } \\
\hline & Good, n (\%) & Poor, n (\%) & & & & \\
\hline \multicolumn{7}{|l|}{ Gender } \\
\hline Male & $44(59.5)$ & $73(46.8)$ & & 1 & 1 & \\
\hline Female & $30(40.5)$ & $83(53.2)$ & 0.07 & 1.67 (0.95 to 2.92$)$ & 1.51 (0.77 to 2.94$)$ & 0.23 \\
\hline \multicolumn{7}{|l|}{ Age (years) } \\
\hline$<25$ & $15(20.3)$ & $29(18.6)$ & & 1 & & \\
\hline $25-34$ & $48(64.9)$ & $100(64.1)$ & 0.84 & 1.09 (0.53 to 2.19$)$ & $1.22(0.46$ to 3.23$)$ & 0.68 \\
\hline$\geq 35$ & $11(14.9)$ & $27(17.3)$ & 0.12 & 1.27 (0.49 to 3.24$)$ & 3.40 (0.93 to 12.48$)$ & 0.07 \\
\hline \multicolumn{7}{|c|}{ Experience (years) } \\
\hline$<5$ & 27 (36.5) & $84(53.8)$ & & 1 & 1 & \\
\hline $5-9$ & $24(32.4)$ & $50(32.1)$ & 0.23 & 0.67 (0.35 to 1.28$)$ & 1.42 (0.57 to 3.52$)$ & 0.45 \\
\hline$\geq 10$ & $23(31.1)$ & $22(14.1)$ & 0.001 & 0.31 (0.15 to 0.64$)$ & 0.36 (0.13 to 0.97$)$ & 0.04 \\
\hline \multicolumn{7}{|l|}{ Profession } \\
\hline Pharmacist & $20(27.0)$ & $26(16.7)$ & & 1 & 1 & \\
\hline Physician & $16(21.6)$ & $26(16.7)$ & 0.61 & 1.25 (0.53 to 2.93$)$ & 2.15 (0.70 to 6.56$)$ & 0.18 \\
\hline Nurse & $38(51.4)$ & $104(66.7)$ & 0.04 & 2.11 (1.06 to 4.20$)$ & 1.36 (0.57 to 3.26$)$ & 0.49 \\
\hline \multicolumn{7}{|l|}{ Attitude } \\
\hline Positive & $50(67.6)$ & $78(50)$ & & 1 & 1 & \\
\hline Negative & $24(32.4)$ & $78(50)$ & 0.01 & 2.08 (1.17 to 3.72 ) & 1.24 (0.59 to 2.59$)$ & 0.57 \\
\hline \multicolumn{7}{|l|}{ Knowledge } \\
\hline Good & 48 (64.9) & $54(34.6)$ & & 1 & 1 & \\
\hline Poor & $26(35.1)$ & $102(65.4)$ & $<0.001$ & 3.49 (1.95 to 6.23$)$ & 2.63 (1.26 to 5.45$)$ & 0.01 \\
\hline \multicolumn{7}{|c|}{ Training provided } \\
\hline Yes & $56(75.7)$ & $45(28.8)$ & & 1 & 1 & \\
\hline No & 18 (24.3) & $111(71.2)$ & $<0.001$ & 7.67 (4.07 to 14.46$)$ & 7.31 (3.42 to 15.62$)$ & $<0.001$ \\
\hline
\end{tabular}

ADR, adverse drug reaction; AOR, adjusted OR.

untrained, which can lead to insufficient knowledge of the ADRs reporting. This represents an important issue that needs to be addressed, the pharmacovigilance centre in Ethiopia should provide training for HCPs. Our study showed that $39.4 \%$ of HCPs were aware of the existence of an ADR system in Ethiopia. This meant that most of the participants did not have information about the authority responsible for monitoring ADRs in Ethiopia. Similarly, lack of knowledge about the national ADR reporting system was reported in different regions of Ethiopia, including a study in Nekemte town which reported that only $30.8 \%$ of the HCPs knew the responsible body for ADRs reporting and in Amhara region that reported 49\% of the HCPs knew the national ADR reporting system. ${ }^{21} 22$ This is a critical observation, which is undoubtedly related to the current underreporting of ADRs.

Regarding the level of attitude, we found that about $60 \%$ of HCPs had a positive attitude on ADR and its reporting. Although the majority of the respondents had positive attitude, the result is lower compared with previous findings in Amhara region of Ethiopia (86\%) by
Seid $e t a l .^{21}$ This difference could be due to differences in the measure of attitude in the two studies. In the study by Seid $e t$ al, an arbitrary cut-off value greater than $75 \%$ was used to classify participants with a positive or negative attitude while using the median value in our study. Most respondents (67.4\%) felt that adverse reactions reporting is necessary, which is consistent with previous studies. ${ }^{2021}$ However, $64.8 \%$ of the respondents agreed that reporting creates an additional workload, which is higher than the results obtained in the Amhara region (32.4\%). ${ }^{21}$ Although it may take some time to complete the report forms, the high proportion of respondents with such perception found in our study may affect the motivation to report adverse reactions. HCPs should consider ADRs reporting as an obligation and should be aware of the existing pharmacovigilance systems.

Another important finding was that ADRs reporting practices among HCPs were very poor. Although more than $75 \%$ of respondents encountered one or more ADRs in their daily practice, only $32.1 \%$ of respondents reported ADRs. This is consistent with a study conducted 
in west Ethiopia which found only $38.8 \%$ of the participants reported ADRs. ${ }^{22}$ Many factors were mentioned as reasons for under-reporting of ADRs. A study in eastern Ethiopia found that unavailability of reporting form $(53.9 \%)$, uncertainty of how to report $(51.9 \%)$ and lack of feedback from the responsibe body $(41 \%)$ were the reasons for under-reporting. ${ }^{20}$ Similarly, lack of awareness and knowledge on what, when and to whom to report ADRs (30.8\%) and lack of commitments from HCPs $(25.5 \%)$ were the reason for under-reporting of ADRs in a study in West Ethiopia. ${ }^{22}$

The study also identified the predictors of poor ADR reporting practices. Less experienced HCPs were more likely to have poor ADR reporting practices. This finding is consistent with a study conducted in Uganda, where more experienced HCPs were four times more likely to have ever reported than less experienced professionals. ${ }^{23}$ Health professionals with poor knowledge were more likely to have a poor practice of ADRs reporting. The association of poor knowledge levels of health professionals with poor ADR reporting practice has been observed in many similar previous studies. ${ }^{23-27}$ Moreover, health professionals who had not received ADRs reporting training were more likely to have poor practice. This is also supported by a study carried out in Spain. ${ }^{28}$ However, only $44.95 \%$ of the respondents were trained in our study. Similarly, HCPs have shown limited training in areas of ADR and their reporting in studies conducted in Sudan ${ }^{25}$ and Uganda. ${ }^{23}$ Thus, more training regarding the identification of $\mathrm{ADR}$, the purpose of the $\mathrm{ADR}$ reporting and the availability of resources for ADR reporting is required.

These findings have important implications. The low level of knowledge of the ADR and its reporting among HCPs should be enhanced by designing different strategies. A systematic review of strategies to improve ADRs reporting has shown that multiple interventions appear to have had more impact than single interventions. ${ }^{13}$ Several studies have shown improved knowledge and attitude scores after educational interventions, including oral workshops, oral presentations, group discussions, designing ADR newsletters in hospitals and ongoing training in pharmacovigilance and ADR reporting. ${ }^{29-33}$ Other studies have shown that ADRs reporting has been improved by offering incentives to health professionals. ${ }^{34}{ }^{35}$ A study conducted in Spanish that involves both economic incentives and educational activities, resulted in up to a sixfold increase in the average ADR reporting. ${ }^{36}$ Increasing the availability of yellow cards on wards as well as encouragement to use web-based reporting had improved reporting rates. ${ }^{37}$ Therefore, empowering HCPs in detecting and reporting suspected drug reactions and using strategies that are evidencebased is essential to strengthening pharmacovigilance systems in Ethiopia. This is especially important for less experienced health professionals and for those who had never received training on ADR reporting. However, additional research needs to be done to investigate the impact of these interventions on the knowledge and practice of ADR reporting in our setting.

Finally, there are several limitations to this study. We used a self-report as the main method of inquiry, which may have introduced recall bias. The HCPs may have made explicit responses to the fear that they would be embarrassed if they did not report ADRs. However, because we used self-administered questionnaires without respondents' names, the potential for this bias was reduced. The cross-sectional design we used may not establish a causal relationship between ADR reporting and explanatory variables. Finally, the study was conducted in a tertiary referral hospital and may not be generalised for all HCPs in different healthcare levels in the country. Despite these limitations, our study has generated important insights on knowledge, attitude and practice of ADR reporting and predictors of poor ADRs reporting practice.

\section{CONCLUSION}

The majority of health professionals had poor knowledge and practice, but a positive attitude towards ADRs reporting. Poor knowledge, less work experience and lack of training were predictors of poor ADR reporting practice. Therefore, strategies to improve knowledge and practices regarding ADR reporting should be implemented. Training should be provided to all HCPs, especially those who have never received training and less experienced professionals.

Acknowledgements The authors would like to thank College of Health Science, Mekelle University for their support and cooperation. The authors would also like to thank for all Ayder comprehensive specialised hospital staff members for their willingness to participate and dedicate their valuable time to fill the questionnaire.

Contributors KG and MS conceived the study and drafted the manuscript and contributed to data entry, data analysis, draft manuscript and final proof reading. BYH, SWA and YLN participated in study design, data analysis and in the process of manuscript writing. All authors approved the final manuscript.

Funding The authors have not declared a specific grant for this research from any funding agency in the public, commercial or not-for-profit sectors.

Competing interests None declared.

Patient consent for publication Not required.

Ethics approval The ethical approval and clearance were obtained from the Ethics Review Committee of the School of Pharmacy, College of Health Sciences, Mekelle University (reference number: CHS/161/pharm-11). In addition, a brief description of the objective of the study was provided for all the participants to avoid ambiguity and misunderstanding. The data collection process was initiated after the willingness of the health professionals was requested and formal written consent was obtained.

Provenance and peer review Not commissioned; externally peer reviewed.

Data availability statement The dataset of this study is available from the corresponding author upon request.

Open access This is an open access article distributed in accordance with the Creative Commons Attribution Non Commercial (CC BY-NC 4.0) license, which permits others to distribute, remix, adapt, build upon this work non-commercially, and license their derivative works on different terms, provided the original work is properly cited, appropriate credit is given, any changes made indicated, and the use is non-commercial. See: http://creativecommons.org/licenses/by-nc/4.0/.

ORCID iD

Kidu Gidey http://orcid.org/0000-0002-7363-1327 


\section{REFERENCES}

1 Bouvy JC, De Bruin ML, Koopmanschap MA. Epidemiology of adverse drug reactions in Europe: a review of recent observational studies. Drug Saf 2015;38:437-53.

2 Campbell JE, Gossell-Williams M, Lee MG. A review of pharmacovigilance. West Indian Med J 2014;63:771-4.

3 Angamo MT, Chalmers L, Curtain CM, et al. Adverse-DrugReaction-Related hospitalisations in developed and developing countries: a review of prevalence and contributing factors. Drug Saf 2016;39:847-57.

4 Organization WH. Safety of medicines: a guide to detecting and reporting adverse drug reactions: why health professionals need to take action. Geneva: World Health Organization, 2002.

5 Huang Y-L, Moon J, Segal JB. A comparison of active adverse event surveillance systems worldwide. Drug Saf 2014;37:581-96.

6 Sabblah GT, Akweongo P, Darko D, et al. Adverse drug reaction reporting by doctors in a developing country: a case study from Ghana. Ghana Med J 2014;48:189-93.

7 Hazell L, Shakir SAW. Under-reporting of adverse drug reactions : a systematic review. Drug Saf 2006;29:385-96.

8 Lopez-Gonzalez E, Herdeiro MT, Figueiras A. Determinants of underreporting of adverse drug reactions: a systematic review. Drug Saf 2009;32:19-31.

9 Onakpoya IJ, Heneghan CJ, Aronson JK. Post-marketing withdrawa of 462 medicinal products because of adverse drug reactions: a systematic review of the world literature. BMC Med 2016;14:10.

10 Zolezzi M, Parsotam N. Adverse drug reaction reporting in New Zealand: implications for pharmacists. Ther Clin Risk Manag 2005;1:181.

11 Al Dweik R, Stacey D, Kohen D, et al. Factors affecting patient reporting of adverse drug reactions: a systematic review. $\mathrm{Br} \mathrm{J}$ Clin Pharmacol 2017;83:875-83.

12 Pérez García M, Figueras A. The lack of knowledge about the voluntary reporting system of adverse drug reactions as a major cause of underreporting: direct survey among health professionals. Pharmacoepidemiol Drug Saf 2011;20:1295-302.

13 Gonzalez-Gonzalez C, Lopez-Gonzalez E, Herdeiro MT, et al. Strategies to improve adverse drug reaction reporting: a critical and systematic review. Drug Saf 2013;36:317-28.

14 Alshammari TM, Alamri KK, Ghawa YA, et al. Knowledge and attitude of health-care professionals in hospitals towards pharmacovigilance in Saudi Arabia. Int J Clin Pharm 2015;37:1104-10.

15 Alshami M, Azm M. The need of pharmacovigilance activities in Yemen. Glob J Med Res 2014.

16 Mulatu WN, Worku A. Assessment of knowledge, attitude and practice of health professionals towards adverse drug reaction reporting and factors associated with reporting. J Pharmacovigil 2014.

17 Necho Mulatu W. Assessment of knowledge, attitude and practice of health professionals towards adverse drug reaction reporting and factors associated with reporting. J Pharmacovigil 2014;02.

18 Nisa ZU, Zafar A, Sher F. Assessment of knowledge, attitude and practice of adverse drug reaction reporting among healthcare professionals in secondary and tertiary hospitals in the capital of Pakistan. Saudi Pharm J 2018;26:453-61.

19 Güner MD, Ekmekci PE. Healthcare professionals' pharmacovigilance knowledge and adverse drug reaction reporting behavior and factors determining the reporting rates. J Drug Assess 2019;8:13-20.
20 Shanko H, Abdela J. Knowledge, attitudes, and practices of health care professionals toward adverse drug reaction reporting in Hiwot Fana specialized university Hospital, Harar, eastern Ethiopia: a crosssectional study. Hosp Pharm 2018;53:177-87.

21 Seid MA, Kasahun AE, Mante BM, et al. Healthcare professionals knowledge, attitude and practice towards adverse drug reaction (ADR) reporting at the health center level in Ethiopia. Int J Clin Pharm 2018;40:895-902.

22 Gurmesa LT, Dedefo MG. Factors affecting adverse drug reaction reporting of healthcare professionals and their knowledge, attitude, and practice towards ADR reporting in Nekemte town, West Ethiopia. Biomed Res Int 2016;2016:1-6.

23 Katusiime B, Semakula D, Lubinga SJ. Adverse drug reaction reporting among health care workers at Mulago national referral and teaching hospital in Uganda. Afr Health Sci 2015;15:1308-17.

24 Ohaju-Obodo JO, Iribhogbe OI. Extent of pharmacovigilance among resident doctors in Edo and Lagos states of Nigeria. Pharmacoepidemiol Drug Saf 2010;19:191-5.

25 Elnour AA, Ahmed AD, Yousif MAE, et al. Awareness and reporting of adverse drug reactions among health care professionals in Sudan. Jt Comm J Qual Patient Saf 2009;35:324-AP2.

26 Hazell L, Shakir SAW. Under-Reporting of adverse drug reactions. Drug Safety 2006;29:385-96.

27 Green CF, Mottram DR, Rowe PH, et al. Attitudes and knowledge of hospital pharmacists to adverse drug reaction reporting. $\mathrm{Br} J$ Clin Pharmacol 2001;51:81-6.

28 Irujo M, Beitia G, Bes-Rastrollo $\mathrm{M}$, et al. Factors that influence underreporting of suspected adverse drug reactions among community pharmacists in a Spanish region. Drug Saf 2007;30:1073-82.

29 Jha N, Rathore DS, Shankar PR, et al. Effect of an educational intervention on knowledge and attitude regarding pharmacovigilance and consumer pharmacovigilance among community pharmacists in Lalitpur district, Nepal. BMC Res Notes 2017;10:4

30 Bisht M, Singh S, Dhasmana DC. Effect of educational intervention on adverse drug reporting by physicians: a cross-sectional study. ISRN Pharmacol 2014;2014:1-8.

31 Li Q, Zhang S-min, Chen H-ting, et al. Awareness and attitudes of healthcare professionals in Wuhan, China to the reporting of adverse drug reactions. Chin Med J 2004;117:856-61.

32 Rajesh R, Vidyasagar S, Varma DM. An educational intervention to assess knowledge attitude practice of pharmacovigilance among health care professionals in an Indian tertiary care teaching hospital. Int J Pharm Tech Res 2011;3:678-92.

33 Khalili H, Mohebbi N, Hendoiee N, et al. Improvement of knowledge, attitude and perception of healthcare workers about ADR, a preand post-clinical pharmacists' interventional study. BMJ Open 2012;2:e000367.

34 Ali S, Egunsola O, Al-Dossari DS, et al. Adverse drug reaction reporting in a large tertiary hospital in Saudi Arabia: results of an incentive strategy. Ther Adv Drug Saf 2018;9:585-90.

35 Chang F, Xi Y, Zhao J, et al. A time series analysis of the effects of financial incentives and mandatory clinical applications as interventions to improve spontaneous adverse drug reaction reporting by hospital medical staff in China. J Eval Clin Pract 2017;23:1316-21.

36 Pedrós C, Vallano A, Cereza G, et al. An intervention to improve spontaneous adverse drug reaction reporting by hospital physicians: a time series analysis in Spain. Drug Saf 2009;32:77-83.

37 Molokhia M, Tanna S, Bell D. Improving reporting of adverse drug reactions: systematic review. Clin Epidemiol 2009;1:75-92. 